\title{
Influences of Specimen Geometry and Loading Rate on Compressive Strength of Unstabilized Compacted Earth Block
}

\author{
Guan-qi Lan, Yi-hong Wang ${ }^{D}$, and Si-si Chao \\ School of Civil Engineering, Chang'an University, Middle-section of Nan'er Huan Road, Xi'an, Shaanxi 710064, China \\ Correspondence should be addressed to Yi-hong Wang; 2016028001@chd.edu.cn
}

Received 12 April 2018; Accepted 20 June 2018; Published 5 July 2018

Academic Editor: Carlo Santulli

Copyright (C) 2018 Guan-qi Lan et al. This is an open access article distributed under the Creative Commons Attribution License, which permits unrestricted use, distribution, and reproduction in any medium, provided the original work is properly cited.

Loading rate and specimen geometry are critical parameters used in simple compressive tests to determine the strength of earth materials. In this study, cubic and cylindrical unstabilized compacted earth block of different sizes were manufactured and tested in unconfined compression to investigate the size and shape effects on the compressive strength of earth materials under different loading rates. The correlation between the compressive strength of earth materials and the geometric parameters of the specimen was determined. The recommended loading rate and sample for testing the compressive strength of earth materials were given. Finally, a constitutive model for describing the stress-strain response of earth materials was proposed. This model modifies the defects of the constitutive equations suggested in previous studies and may be applied to the numerical analysis of earth structure.

\section{Introduction}

Earth as a natural building material has been widely used all over the world [1], and it can be attributed to the many advantages such as low cost, excellent thermal performance, and easy to use local materials [2]. However, compared with industrial building materials like concrete, earth materials have the apparent deficiency in physical property, mechanical property, and durability $[3,4]$. It hindered the development and application of earth materials in the field of construction. Due to the improvement in people's attention to the environment, the problem of sustainable development has attracted much attention in the field of civil engineering. Meanwhile, the application of low-cost and sustainable materials in construction has become the focus of research $[5,6]$. Consequently, earth materials have attracted people's attention again attributing to its ecological benefits and widespread regional adaptability [7-9]. Compressive strength is the most important mechanical property of earth materials and one of the fundamental mechanical parameters required for earth structure design. Therefore, accurate measurement of the compressive strength of earth materials was of high research and engineering significance. However, in most of the existing study, the size and shape of the specimen for determining the uniaxial compressive strength of earth materials were different, and the loading rates used in the simple compressive test were not uniform [10-13]. It has been noted that the experimental conditions, such as specimen shape, size, and loading rate, significantly influence testing results, and the differences in test conditions make it difficult to compare the previous results.

Platen restraint is one of the reasons that cause the specimen geometry effect on compressive strength. The treatment method of geometrical effects used in both New Zealand [14] and Australia [15] was to reflect the platen restraint effects through a single aspect ratio correction factor. The advantage of this method was that it can be applied to a variety of different specimen sizes, but it also depended on the accuracy of correction factors. According to the Standards New Zealand "NZS 4298:1998" [14] and Australian handbook [15], the compressive strength of the specimen with an aspect ratio of 2 was 0.88 times the compressive strength of the cube specimen. Morel et al. [16] indicated that another reason for geometrical effects on the compressive strength of earth specimens was the friction during specimen manufacture. They stated that for the samples were produced using single compaction, the density increases with the height close to the compression surface due to friction along the mould sides. 
Several studies reported in the previous literature suggested that the compressive strength of earth materials with comparability can be obtained by standardizing the size and shape of the specimens. Silveira et al. [17] established the relationship between the compressive strength of cubic specimens and the compressive strength of the cylinder, with a correction factor of about 0.94 for converting the cube strength to cylinder strength. They also concluded that the slight difference in the compressive strength of the specimens with different shapes could be minimized by the regularization mortar at the end of specimens. However, the testing specimens were taken from the existing adobe building in Aveiro district, Portugal, which caused the high variability of results. Ciancio and Gibbings [11] measured the compressive strength of cement-stabilized rammed earth by simple compression test of the specimen with slenderness ratio equal to 2 . Due to the limited number of specimens, the results failed to reflect the effect of the specimen size on compressive strength. Meanwhile, they found that the cylinder specimens with loading end contact with the steel plate show an evident slenderness effect, but the slenderness effect was substantially eliminated after the steel plate was replaced by the Teflon sheet. Aubert et al. [18] measured the compressive strength of small cube specimens dry sawn from earth bricks. Because the practical implementation of the manufacturing process was rather difficult, he advised against using this method to obtain the compressive strength of earth brick. However, this problem is easily solved by making test specimens with the same process as the brick. Although the test results with comparability can be obtained by using a standard test specimen, the shape and size of the standard specimen still need further study.

Loading rate effects on the mechanical properties of earth materials play an essential part in the measurement of material compressive strength. However, a small amount of test data has now been acquired for earth materials under a wide range of loading rates. According to results by unconfined compression test for frozen soil, Chen et al. [19] found that compressive strength increased $100 \%$ in average when loading rates rose from $5 \times 10^{-5}$ to $1 \times 10^{-3}$ and proposed (1) to correlate the compressive strength $f_{\mathrm{c}}$ with loading rates:

$$
f_{\mathrm{c}}=A\left(\frac{\dot{v}}{\dot{v}_{0}}\right)^{n}
$$

where $\dot{v}$ represents loading rate, $\dot{v}_{0}$ represents benchmark loading rate, $A$ is a temperature-related parameter, and $n$ is an index. After the analysis by Chen et al., Du et al. [20] suggested that the elasticity modulus of the frozen soil increased with the loading rate in a specific range, but when the loading rate exceeded this range, the modulus of elasticity decreased with the loading rate. The above studies were focused on frozen soil, and the analysis of the reasons for loading rate effect was not given. For concrete-like materials, a significant number of studies indicated that the enhancement of compressive strength at high loading rate was mainly caused by a combination of fundamental material behavior and inertial confinement effects [21-23]. These

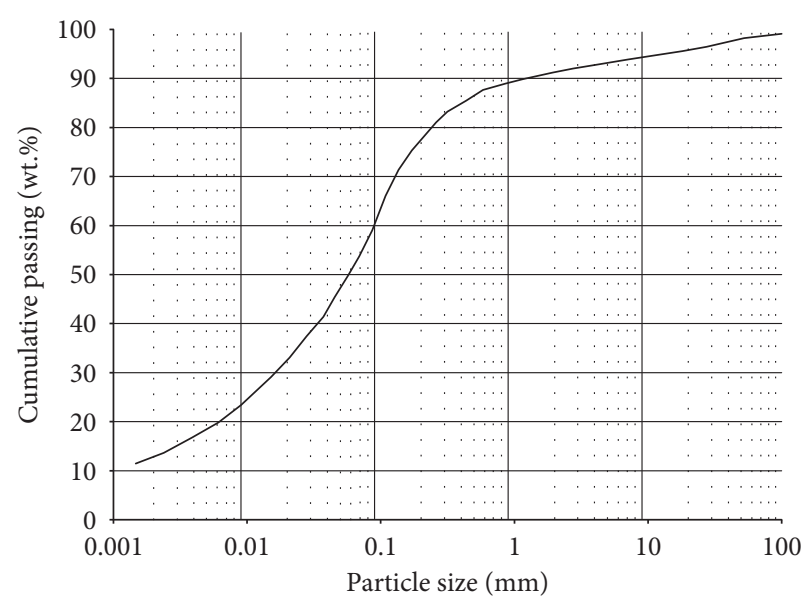

FIgURE 1: Particle size distribution of soil.

analyses provided a reference for the study of the loading rate effect on earth materials.

At present, only a few countries have given the recommended loading rate for the simple compression test of earth materials. The loading rate used in most of the simple compression tests of earth materials was carried out according to the test method for the strength of concrete and stone [24]. Consequently, the study on loading rate effect of earth materials and determination of standard loading rate used in uniaxial compression test has emerged as an urgent issue.

This study performed simple compression tests on cubic and cylindrical compressed earth blocks (CEBs) to investigate the influences of specimen size, specimen shape, and loading rate on the compressive properties of earth materials. The empirical relations between geometric parameters of the specimen and compressive strength were established. The failure patterns and failure mechanism of different specimens in simple compression tests were analyzed. Besides, the constitutive model for describing CEB's stress-strain behavior under compression was proposed.

\section{Materials and Methods}

2.1. Materials. The CEBs tested were produced using soil collected from the region of Xi'an in China. The particle analysis test and limit water content test were carried out following Specification of Soil Test (SL237-1999) [25] to obtain composition and Atterberg limits of soil particles. Figure 1 shows the grain size distribution of the tested soil. The composition of the soil was as follows: $17.6 \%$ clay $(<5 \mu \mathrm{m}), 38.5 \%$ silt $(5-75 \mu \mathrm{m}), 36.1 \%$ sand $(75-2000 \mu \mathrm{m})$, and $7.8 \%$ gravel $(>2000 \mu \mathrm{m})$. Atterberg limits of soil were obtained as follows: $W_{\mathrm{L}}=33.6 \%$ (liquid limit), $W_{\mathrm{P}}=17.2 \%$ (plastic limit), and $I_{\mathrm{P}}=16.4 \%$ (plasticity index). It can be classified as low liquid limit clay (CL) according to the Standard for Engineering Classification of Soil (GB T 501452007) [26]. The optimum moisture content (OMC) and maximum dry density (MDD) of soil were $18.2 \%$ and $1.9 \mathrm{~g} / \mathrm{cm}^{3}$, respectively, and it was also carried out in compliance with SL237-1999 [25]. 
TABLE 1: Number of specimens.

\begin{tabular}{lcccccc}
\hline \multirow{2}{*}{ Label } & \multirow{2}{*}{ Shape } & \multirow{2}{*}{ Size $(\mathrm{mm})$} & \multicolumn{5}{c}{$V_{\mathrm{c}}(\mathrm{mm} / \mathrm{min})$} \\
& & & 1 & 3 & 5 & 7 \\
\hline $\mathrm{Cu}-100$ & & 100 & 10 & 10 & 10 & 10 \\
$\mathrm{Cu}-150$ & Cube & 150 & 10 & 10 & 10 & 10 \\
$\mathrm{Cu}-200$ & & 200 & 10 & 10 & 10 & 10 \\
$\mathrm{Cy}-100$ & Cylinder & 100 & 10 & 10 & 10 & 10 \\
\hline
\end{tabular}

The cross-sectional diameter of cylindrical specimens is equal to the height of it. $V_{c}$, loading rate.

2.2. Specimen Preparation. Cubic CEBs with different sizes $(70.7 \mathrm{~mm}, 100 \mathrm{~mm}, 150 \mathrm{~mm}$, and $200 \mathrm{~mm})$ were used for investigating the size effect on compressive strength of earth materials. Meanwhile, ten cylindrical CEBs were produced as the contrast group. The number of specimens, per size, shape, and type of test are indicated in Table 1.

Test specimens were compacted by a hydraulic Jack. Details of the preparation of these specimens were stated below:

(i) The soil was dried in an oven and sieved through a $5 \mathrm{~mm}$ screen. The optimum moisture content of soil (18.2\%) was chosen as the compaction moisture content to make the density of specimen reach the maximum dry density of soil. Water was evenly spread to the soil until the optimum moisture content was reached.

(ii) The wet soil was filled with the steel mould and compacted in two layers. The mass of the damp soil in each layer was controlled to ensure that the maximum dry density was obtained. The close contact between the two layers was secured by rough surface treatment on the first layer of compacted soil.

(iii) The specimen was removed from the mould after the compaction process. The curing of CEB was realized in a homothermal chamber at a temperature of $26 \pm 2^{\circ} \mathrm{C}$ and relative humidity higher than $60 \%$. After 28-day curing, the weight of the CEB must be kept constant before starting the test. The average dry density of the specimen was $1.88 \mathrm{~g} / \mathrm{cm}^{3}$. The average water content of the specimen at the time of the test was $5.62 \%$.

2.3. Test Device and Procedure. An electrohydraulic servo testing machine with the extern digital controller was used to measure the compressive strength of CEB. The max load of the testing machine was $300 \mathrm{kN}$. The force-displacement curve of specimens can be automatically drawn by the computer system.

The testing procedures, in this case, were referenced in the Test Method of Mechanical Properties on Ordinary Concrete (GB/T 50081-2002) [27]. Because the CEB has strong deformability but low strength, the displacement control was adopted in loading. Four loading rates $(1 \mathrm{~mm} / \mathrm{min}, 3 \mathrm{~mm} / \mathrm{min}, 5 \mathrm{~mm} / \mathrm{min}$, and $7 \mathrm{~mm} / \mathrm{min})$ were selected to investigate the influence of loading rate on CEB. A total of 160 specimens were examined.
TABLE 2: Mechanical properties of CEB.

\begin{tabular}{lcccc}
\hline Label & $V_{\mathrm{c}}(\mathrm{mm} / \mathrm{min})$ & $f_{\text {mean }}(\mathrm{MPa})$ & $\mathrm{CV}$ & $\varepsilon_{\mathrm{bc}} \cdot 10^{-2}$ \\
\hline \multirow{4}{*}{$\mathrm{Cu}-100$} & 1 & 3.24 & 0.37 & 2.64 \\
& 3 & 3.64 & 0.25 & 2.86 \\
& 5 & 2.90 & 0.54 & 2.74 \\
$\mathrm{Cu}-150$ & 7 & 2.81 & 0.37 & 2.62 \\
& 1 & 2.46 & 0.32 & 2.54 \\
& 3 & 2.30 & 0.19 & 2.68 \\
& 5 & 1.82 & 0.33 & 2.90 \\
$\mathrm{Cu}-200$ & 7 & 2.03 & 0.22 & 2.94 \\
& 1 & 1.54 & 0.19 & 3.68 \\
& 3 & 1.44 & 0.22 & 3.32 \\
& 7 & 1.27 & 0.28 & 5.40 \\
$\mathrm{Cy}-100$ & 1 & 1.11 & 0.17 & 6.05 \\
& 3 & 2.71 & 0.14 & 2.71 \\
& 5 & 2.73 & 0.15 & 2.51 \\
& 7 & 3.13 & 0.18 & 2.47 \\
& 5 & 2.96 & 0.22 & 2.73 \\
\hline
\end{tabular}

$f_{\text {mean }}$ is the average of each group after the abnormal values were eliminated. $\mathrm{CV}$ is coefficient of variation of the compressive strength. $\varepsilon_{\mathrm{bc}}$ is the strain corresponding to the peak load.

The unconfined compressive strength $\left(f_{\mathrm{cu}} / \mathrm{MPa},(2)\right)$ was defined as the ratio of the maximum axial force $\left(F_{\max } / \mathrm{N}\right)$ to the compressed area $\left(A / \mathrm{mm}^{2}\right)$ :

$$
f_{\mathrm{cu}}=\frac{F_{\max }}{A} \text {. }
$$

The Grubbs statistics theory was used to eliminate the abnormal values in each group of unconfined compressive strength. For example, the compressive strength $(\mathrm{MPa})$ of ten cubic specimens with the size of $150 \mathrm{~mm}$ was $2.47,2.62$, $2.49,2.16,2.06,1.60,2.18,2.40,2.12$, and 2.23 , respectively. The maximum, minimum, mean, and standard deviation of the above data were $2.62,1.60,2.53$, and 0.27 , respectively. The Grubbs test statistic was defined as the ratio of the residual to the standard deviation and calculated from the following equation:

$$
\begin{aligned}
& G_{n}^{\prime}=\frac{\left(\sigma_{\text {max }}-\sigma_{\text {mean }}\right)}{S_{\sigma}}=0.33, \\
& G_{n}=\frac{\left(\sigma_{\text {mean }}-\sigma_{\text {min }}\right)}{S_{\sigma}}=3.07,
\end{aligned}
$$

where $\sigma_{\min }$ is the minimum compressive strength, $\sigma_{\max }$ is the maximum compressive strength, $\sigma_{\text {mean }}$ is mean of compressive strength, $S_{\sigma}$ is the standard deviation of compressive strength, $n$ is the number of specimens, and $G_{\mathrm{n}}$ and $G_{n}^{\prime}$ are Grubbs test statistics. The reject level $(\alpha)$ was selected as 0.05 , and the corresponding discriminant value was $G_{0.95}=2.176$. The $\sigma_{\min }(1.60)$ was judged to be an abnormal value and was eliminated due to $G_{n}>G_{n}^{\prime}$ and $G_{n}>G_{0.95}$. The above steps were used to judge the remaining data until the abnormal values in the group were eliminated. Table 2 lists the mean and characteristic values of CEB's compressive strength. 


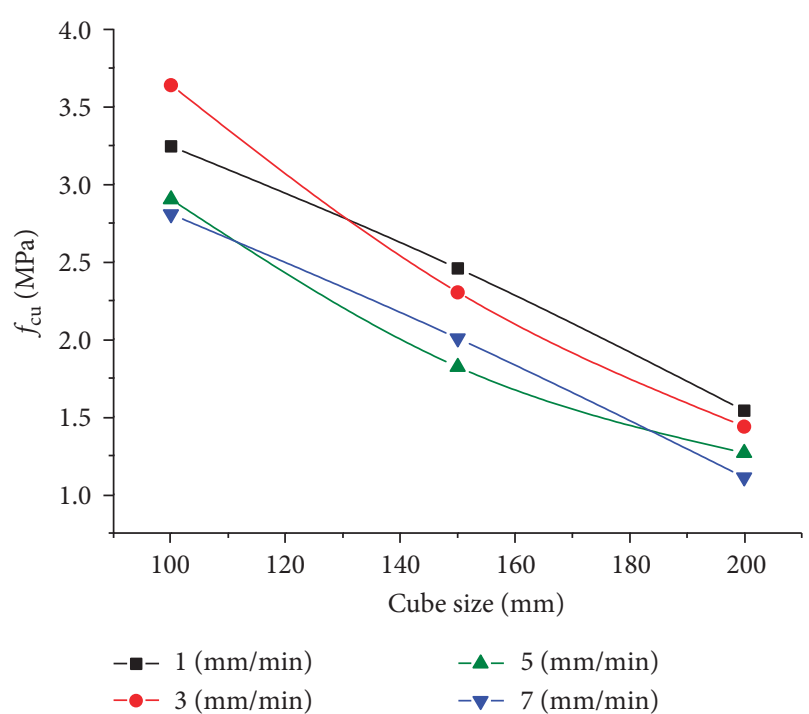

Figure 2: Compression strengths of differently sized cubes.

\section{Results and Discussion}

3.1. The Influence of Specimen Size on Compressive Strength. The mean compressive strengths of different size cube specimens were obtained after the abnormal values were eliminated. Figure 2 shows the results of the unconfined compression tests with loading rates ranging from $1 \mathrm{~mm} / \mathrm{min}$ to $7 \mathrm{~mm} / \mathrm{min}$ on differently sized cubes. The $x$ axis indicates the size of the cubic specimen, and the $y$-axis indicates the mean of compressive strength. As expected, this figure shows the significant influence of specimen size on the compressive strength of CEB. The compressive strength decreased as the specimen size increased at four different loading rates. For the cube with small size, the compressive strength was greater than $3 \mathrm{MPa}$. In contrast, for the jumbo size, the compressive strength was low, and it decreased to a value of $1.11 \mathrm{MPa}$ for the cubic specimen with a size of $200 \mathrm{~mm}$. Two reasons may cause this. On the one hand, the deformation of the specimen in unconfined compression test is not only along the direction of load but also in the horizontal direction. As the flat deformation of the steel plate is less than the deformation of the specimen, friction is produced between the specimen and the plate. The conflict restricts the horizontal deformation of the specimen, and the strength of CEB is improved. However, this constraint is gradually reduced along the height of specimen. The large size specimen leads to the weakening of the constraint. On the other hand, the probability of defects such as pores, cracks, and partial damages in large specimens is substantial, and it also reduces the strength of CEB.

3.2. The Influence of Specimen Shape on Compressive Strength. The uniaxial compression test results of cubic and cylindrical specimens with the same sectional dimension and height, namely, $100 \mathrm{~mm}$, are shown in Figure 3. The $x$-axis means the loading rate, and the $y$-axis denotes the mean of the compressive strength. This figure shows the slight influence of

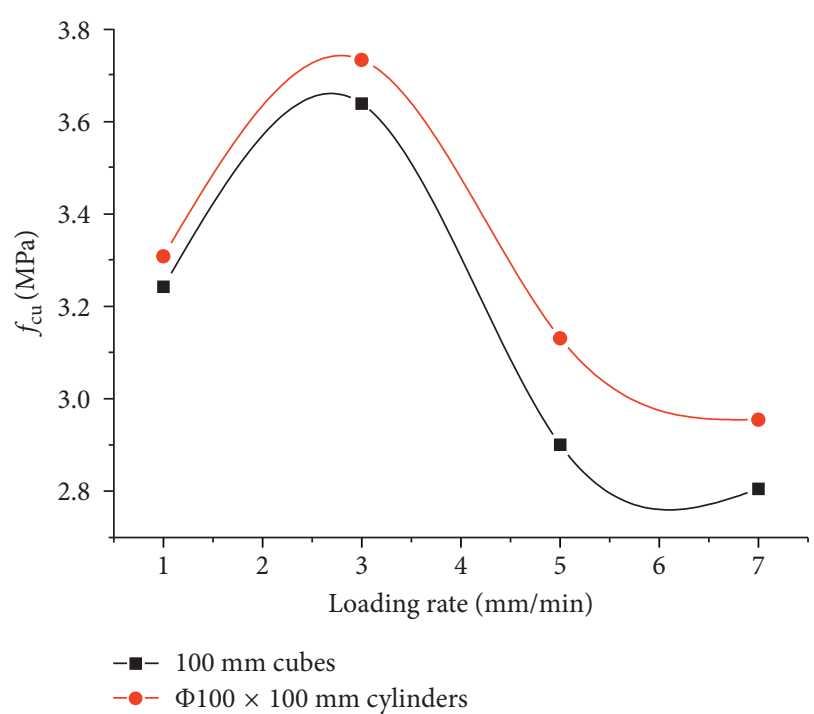

Figure 3: Compression strengths of $100 \mathrm{~mm}$ cubes to $\Phi 100 \times 100 \mathrm{~mm}$ cylinders.

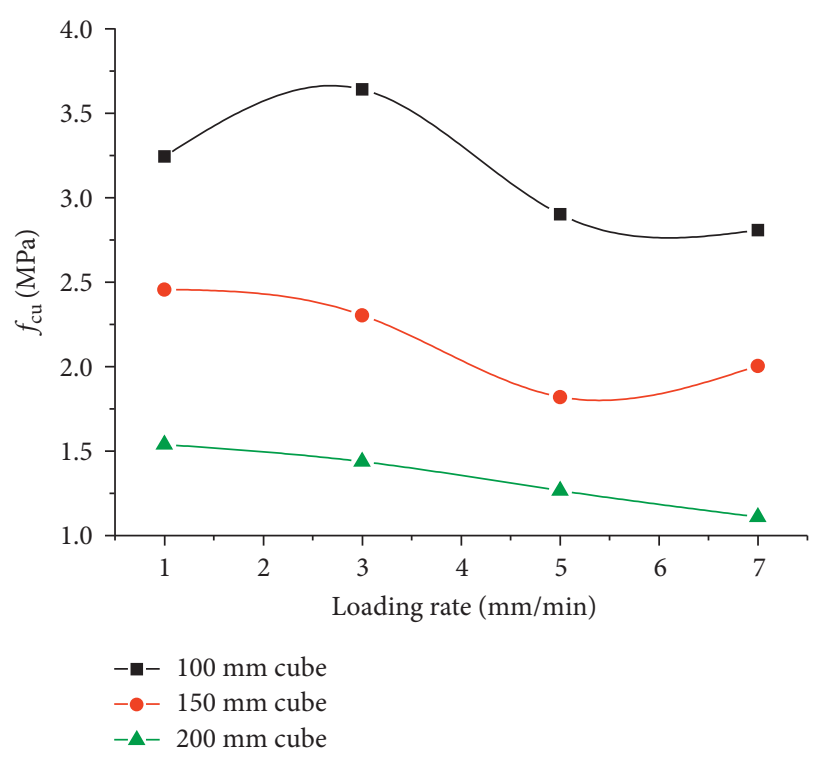

FIgURE 4: Compression strengths of cubes under different loading rates.

the specimen size on the compressive strength, and the cylindrical specimens gave slightly higher compressive strength than the cubic at different loading rates. One possible reason is that the stress concentration appears in the corner of the cubic specimen. Nonetheless, the compressive strength difference between specimens with cylindrical and cubic shapes was trivial under axial loading with loading rate ranging from $1 \mathrm{~mm} / \mathrm{min}$ to $3 \mathrm{~mm} / \mathrm{min}$. The maximum difference in compressive strength was less than $8.4 \%$ at the loading rate of $3 \mathrm{~mm} / \mathrm{min}$, indicating that the effect of specimen shape on compressive strength is negligible.

3.3. The Influence of Loading Rate on the Compressive Strength. The variation of mean compressive strength with loading rate is shown in Figure 4. As can be seen, the 

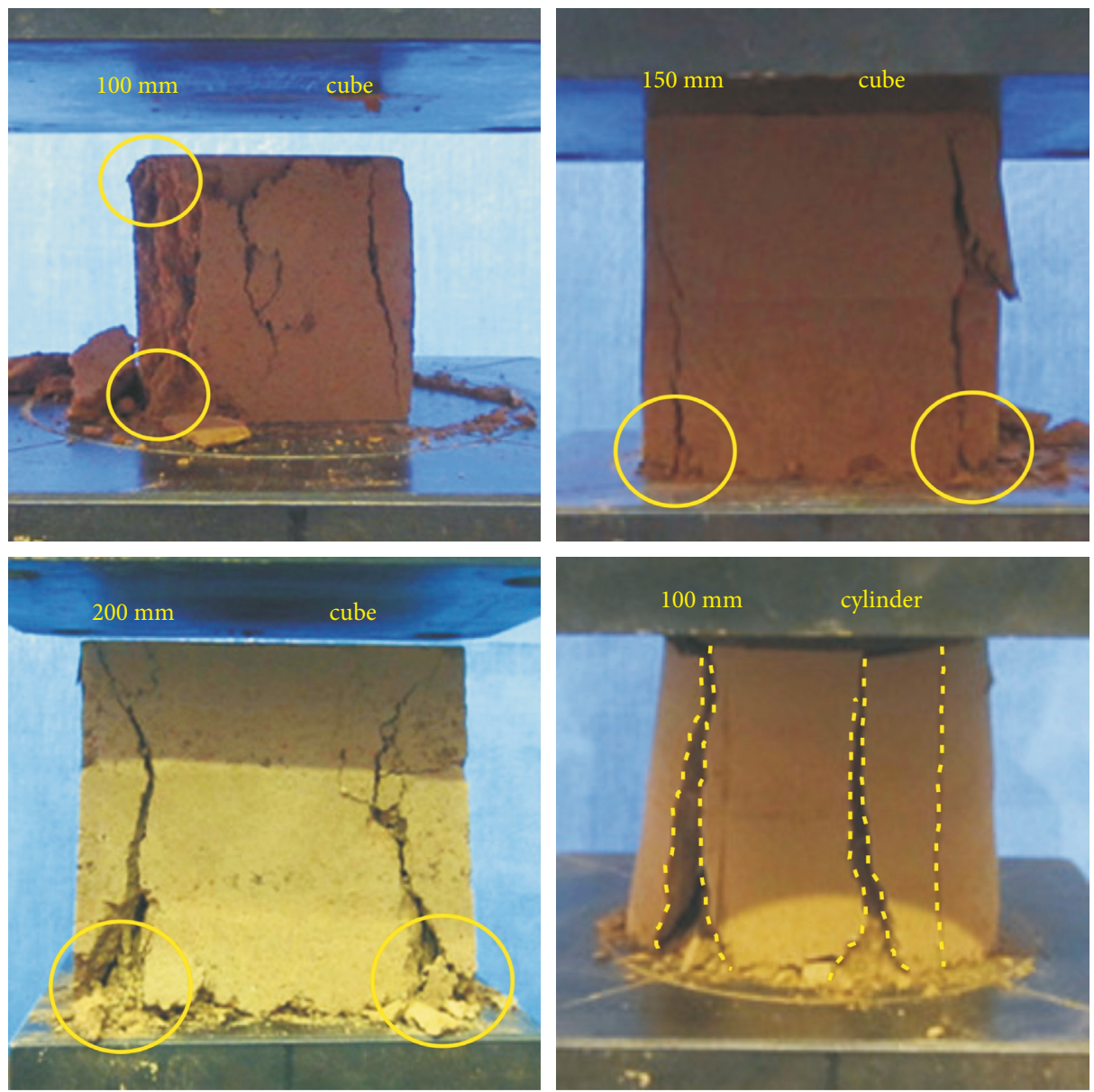

FIGURE 5: The failure patterns of specimens.

compressive strength decreased slightly with the increase of loading rate from $1 \mathrm{~mm} / \mathrm{min}$ to $7 \mathrm{~mm} / \mathrm{min}$, but the loading rate effect is minor in this tests compared to the size effect. The maximum difference of compressive strength between both loading rates is less than $25 \%$. These results were opposite to the loading rate effect on concrete. Existing research results show that the high loading rate caused the internal microcracks in the mortar not fully expanded, which led to the destruction of the concrete aggregate. Higher loading rate resulted in the increase of aggregate destruction and the improvement in concrete strength [22]. However, the failure of soil is due to the appearance of the continuous sliding surface. The high loading rate accelerates the generation and slip of the sliding surface, which leads to the reduction in the CEB strength. It can also be noted that there was a definite difference in the relationship between loading rate and compressive strength at different size cubes. For example, the compressive strength of $100 \mathrm{~mm}$ cubes increased first and then decreased with the increase in loading rate but those of $200 \mathrm{~mm}$ cubes decreased with the increase in loading rate. This phenomenon may be due to the limitation of the range of loading rate, and the rule of compressive strength with loading rate cannot be fully reflected. Moreover, the heterogeneity of earth materials also leads to a significant variability of results.

3.4. Size and Shape Effects on Failure Patterns. Figure 5 shows the failure patterns of specimens with different sizes and shapes after uniaxial compression tests. As it can be noticed, the failure pattern was sensitive to the specimen shape but insensitive to the specimen size. The damage of cubes was mainly due to the cracks in the corner of cubes and the exfoliation of the lateral sides as shown in Figure 5. One cause may be the friction between steel plate and specimen that formed stress concentration on every corner of cubic specimens. In contrast, the stress concentration was relieved on the cylinder specimen because there was no mutation edge in the circular section. For the cylindrical specimens, it is observed that the failures crack showed columnar distribution. Meanwhile, similar to the failure pattern of cubes, the lateral sides of the cylinder specimen were also spalling. This cause of the phenomenon could be that the friction limits the end deformation of specimen followed by expansion producing on the lateral sides of the specimen. The remaining hourglass core is shown in Figure 6 also reflected the influence of boundary confinement. 

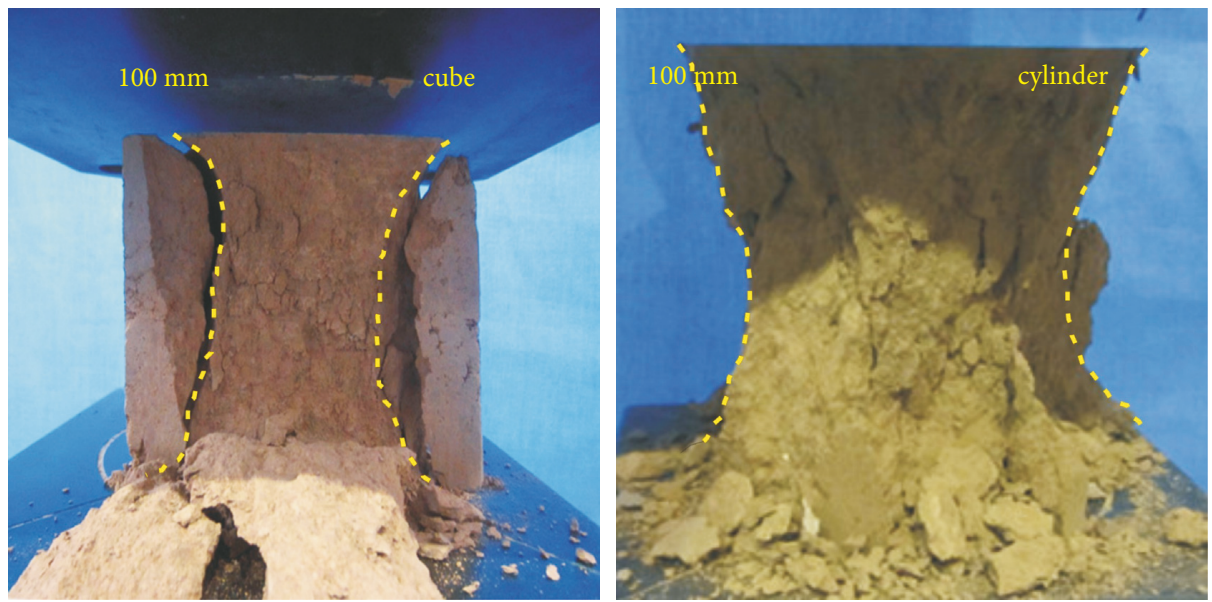

FIgURE 6: The remaining hourglass core of cube and cylinder.

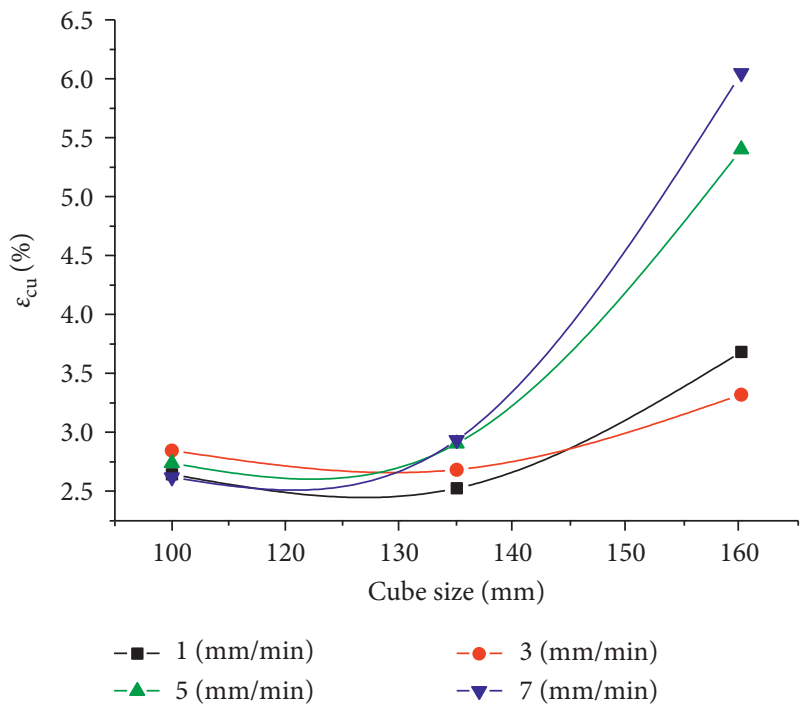

Figure 7: Peak strains of cubes under different loading rates.

3.5. Size and Shape Effects on Peak Strain. The peak strain is defined as the strain corresponding to the peak stress. The mean peak strains of the specimens were obtained in the uniaxial compression tests conducted on cubic specimens. The variation of mean peak strain with loading rate on differently sized cubes is shown in Figure 7. It can be seen that the mean peak strain of small size specimen $(100 \mathrm{~mm}$, $150 \mathrm{~mm}$ ) was less than that of large size specimen $(200 \mathrm{~mm})$. For $100 \mathrm{~mm}$ cubes, the mean peak strain ranged between $2.62 \%(7 \mathrm{~mm} / \mathrm{min})$ and $2.85 \%(3 \mathrm{~mm} / \mathrm{min})$ with a global mean value of $2.71 \%$. By comparison, the mean peak strain of $200 \mathrm{~mm}$ cubes ranged between $3.32 \%(3 \mathrm{~mm} / \mathrm{min})$ and $6.05 \%(7 \mathrm{~mm} / \mathrm{min})$ with a global mean value of $4.61 \%$. This phenomenon is because the large size specimens contained more pores and cracks than small size specimens. These pores and cracks are fully compressed at the peak load, and the increase in compression increased peak strain. Moreover, it can also be noted that the effect of loading rate on the peak strain of large size specimen was more significant than that of small size specimen. The mean peak strain of $150-\mathrm{mm}$

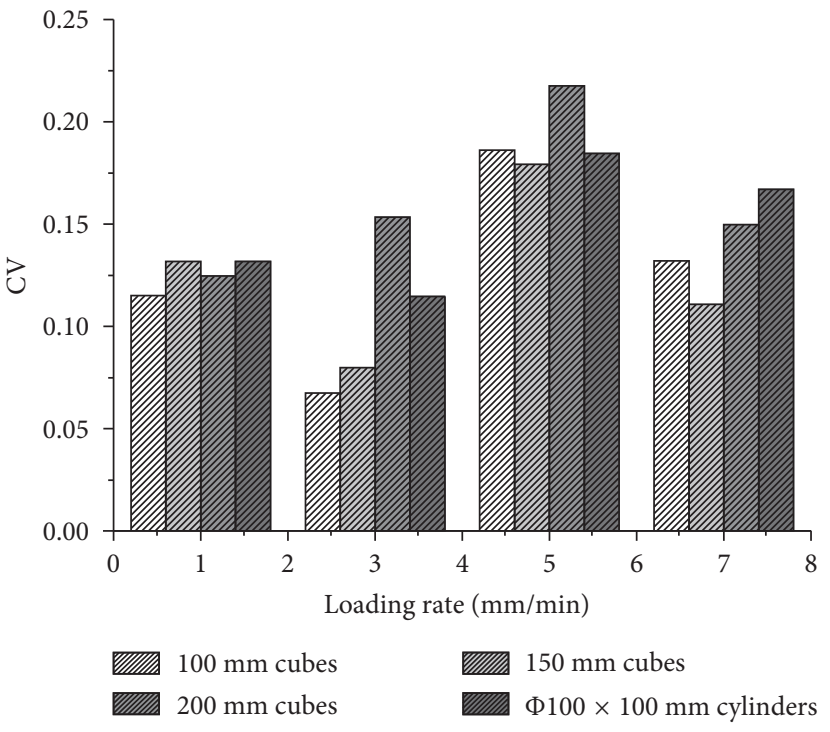

FIgURE 8: CV of compressive strength.

cubes increased only by $0.38 \%$ as the loading rate increased from $1 \mathrm{~mm} / \mathrm{min}$ to $7 \mathrm{~mm} / \mathrm{min}$. However, the mean peak strain of the $200 \mathrm{~mm}$ cubes increased by $2.73 \%$ within the range of loading rate. This phenomenon may be because the high loading rate accelerates the compression of the pores and cracks and increases the compression of the specimen before the formation of the continuous sliding surface.

3.6. Recommended Standard Loading Rate and Standard Specimen. Due to the inhomogeneity of the spatial distribution of the earth materials, the discreteness of the experimental data was notable. The coefficient of variation (CV) of each group of compressive strength was calculated and used to analyze the stability of experimental data. The variation of $\mathrm{CV}$ as specimen size and loading rate is shown in Figure 8 .

It can be observed that the strength $\mathrm{CV}$ of all types of specimens reached the minimum at the loading rate of $3 \mathrm{~mm} / \mathrm{min}$. Consequently, $3 \mathrm{~mm} / \mathrm{min}$ was selected as the 


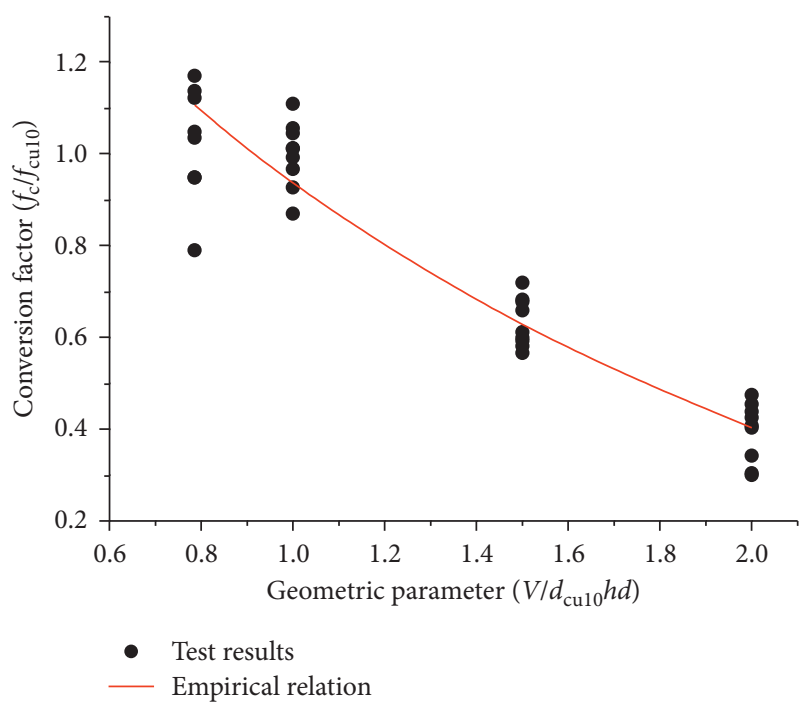

FIGURE 9: Empirical relation of conversion factors for compressive strength.

standard loading rate of compression test of earth materials. Meanwhile, it can also be noted that the strength CV of $100 \mathrm{~mm}$ cubic specimen was less than that of other specimens. Based on the results, it was suggested that the standard specimen for compression test of earth materials was $100 \mathrm{~mm}$ cubic specimen.

\subsection{Correlations}

3.7.1. The Relationship of Compressive Strength of Specimens with Different Shape and Size. A conversion coefficient was introduced to quantify the effects of shape and size of specimens on the compressive strength of earth materials. The conversion factor was defined as the ratio of the compressive strength $f_{\mathrm{c}}$ of specimens with various shapes and sizes to $f_{\text {cu10 }}$, the strength of $100 \mathrm{~mm}$ cubic specimen. As the compressive strength was dependent on both the size and shape of the specimens, the empirical relation, in this case, considers the conversion factor as a function of lateral dimension $d$, height $h$, volume $V$, and $h / d$ (ratio of height to lateral dimension) and is proposed in (4):

$$
\frac{f_{\mathrm{c}}}{f_{\mathrm{cu} 10}}=F\left[\frac{V /\left((h / d) \times d^{2}\right)}{V_{\mathrm{cu} 10} /\left(\left(h_{\mathrm{cu} 10} / d_{\mathrm{cu} 10}\right) \times d_{\mathrm{cu} 10}^{2}\right)}\right]=F\left(\frac{V}{d_{\mathrm{cu} 10} h d}\right) .
$$

The variation of the conversion factor $\left(f_{\mathrm{c}} / f_{\mathrm{cu} 10}\right)$ as a function of the geometric parameter $\left(V / d_{\text {culo }} h d\right)$ is shown in Figure 9. The best-fit regression line for test results is given by (5). The corresponding $R^{2}$ value of 0.9025 shows a good correlation between the conversion factor and the parameter.

$$
\frac{f_{\mathrm{c}}}{f_{\text {cul } 10}}=2.13 e^{-0.83\left(V / \mathrm{d}_{\mathrm{cul} 10} \mathrm{hd}\right)}
$$

TABLE 3: The elastic modulus of CEB.

\begin{tabular}{lccc}
\hline Label & $\mathrm{Cu}-100$ & $\mathrm{Cu}-150$ & $\mathrm{Cu}-200$ \\
\hline & 1.688 & 1.863 & 0.711 \\
& 2.177 & 1.301 & 0.518 \\
& 2.000 & 1.363 & 0.726 \\
& 1.755 & 1.564 & 0.703 \\
Elastic modulus (MPa) & 1.750 & 1.317 & 0.570 \\
& 2.061 & 0.955 & 0.534 \\
& 2.084 & 1.223 & 0.923 \\
& 1.678 & 1.733 & 0.556 \\
Mean (MPa) & 2.263 & 1.533 & 0.550 \\
& 1.794 & 1.317 & 0.770 \\
& 1.924 & 1.417 & 0.656 \\
\hline
\end{tabular}

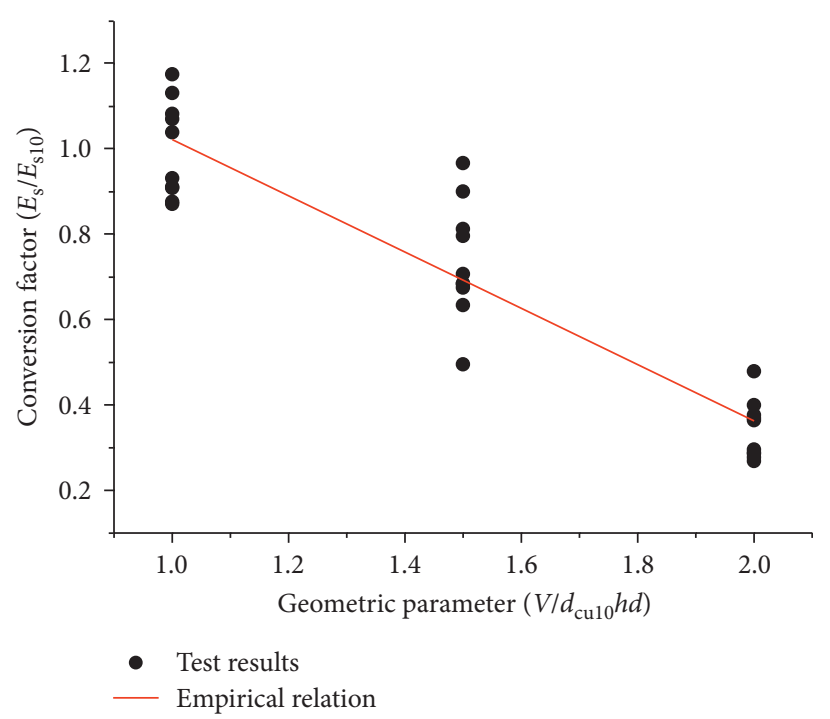

FIgURE 10: Empirical relation of conversion factors for elastic modulus.

3.7.2. The Relationship of the Elastic Modulus of Specimens with a Different Size. Elastic modulus was defined as the slope of the initial linear portion of compressive stress-strain curves of CBD. The elastic modulus of different size cubes at the loading rate of $3 \mathrm{~mm} / \mathrm{min}$ and the mean elastic modulus are shown in Table 3. This Table shows the significant influence of specimen size on the elastic modulus. The mean elastic modulus decreased with the increase in specimen size. It ranged from $0.51 \mathrm{MPa}$ for $200 \mathrm{~mm}$ cube up to $2.26 \mathrm{MPa}$ for $100 \mathrm{~mm}$ cube. It can be explained by the fact that the increase in specimen size is accompanied by an increase in defects, such as pores, cracks, and partial damages, which can weaken the CEB.

The variation of the conversion factor $\left(E_{\mathrm{s}} / E_{\mathrm{s} 10}\right)$ as a function of the geometric parameter $\left(V / d_{\mathrm{cul} 10} h d\right)$ is shown in Figure 10. The best-fit regression line for test results is given by (6):

$$
\frac{E_{\mathrm{s}}}{E_{\mathrm{s} 10}}=-0.66\left(\frac{V}{d_{\mathrm{cu} 10} h d}\right)+1.68
$$




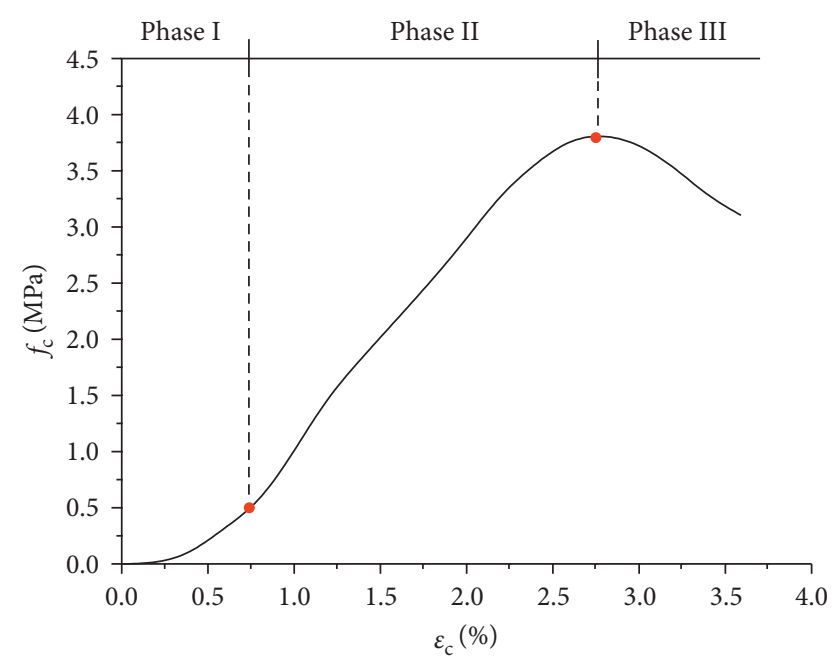

FIgURE 11: Stress-strain diagram of CEB to compression.

3.8. Stress-Strain Curve. Figure 11 shows an example of stress-strain curves for $100 \mathrm{~mm}$ cubic specimens at the loading rate of $3 \mathrm{~mm} / \mathrm{min}$. It can be found that the stressstrain curve can be divided into the following three phases. Initially, a compaction phase occurred, during which, the preexisting protuberance on the surface of the specimen was eliminated. Meanwhile, the specimen underwent recompacted at the initial stage of loading. The cracks and pores existing in the CEBs microstructure were filled with redistributed soil particles. It was noted that the compaction of the specimen occurs in a broad strain range at Phase I. In the second phase, the recompaction process of specimens led to linear stress increase with the growth of strain until the peak stress was reached. After the peak stress was exceeded, the compaction softening effect appears in the earth materials, up to the specimen failure. The reason may be that the continuous sliding surface was produced inside the material.

The results, which were obtained from tests on $100 \mathrm{~mm}$ cubic specimens that loaded at the loading rate of $3 \mathrm{~mm} / \mathrm{min}$, were used to establish the stress-strain relations describing the response of materials to compressive loading. The stress and strain value of CEBs was normalized to propose the constitutive equation of earth materials. The normalized test data are presented in Figure 12. The $x$-axis represents the ratio of axial strains $\varepsilon_{\mathrm{c}}$ to the peak stress, $\varepsilon_{\mathrm{cu}}\left(\bar{\varepsilon}_{\mathrm{c}}=\varepsilon_{\mathrm{c}} / \varepsilon_{\mathrm{cu}}\right)$, and the $y$-axis represents the ratio of normal stresses $f_{\mathrm{c}}$ to the peak stress, $f_{\mathrm{cu}}\left(\bar{f}_{\mathrm{c}}=f_{\mathrm{c}} / f_{\mathrm{cu}}\right)$.

The Weibull equation was adopted for capturing the nonlinear compressive behavior of earth materials. The best Mimic Curve of the test data was determined by selecting the equation corresponding to the maximum of the coefficient of determination $R^{2}$. Moreover, in order to ensure the effectiveness of the equation, the following constraints were proposed: (a) the fitting curve passes through the origin, (b) the fitting curve passes through the point with $\bar{\varepsilon}_{\mathrm{c}}=1$ and $\bar{f}_{\mathrm{c}}=1$, and (c) the continuity of equation and its first derivatives in the variation range of $\bar{\varepsilon}_{\mathrm{c}}$.

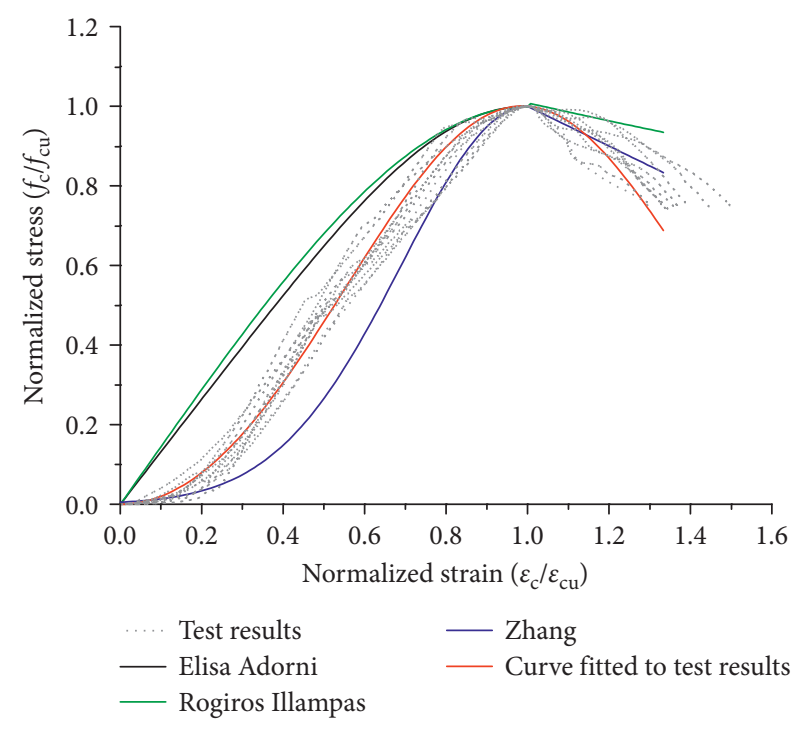

FIgURE 12: Normalized stress-strain test results obtained from compression tests on ten cubic specimens. The curves fitted to these data are compared to other three models.

The fitting curve that satisfies the above conditions was obtained using standard optimization routines of MATLAB, and the corresponding equation is shown below:

$$
\bar{f}_{\mathrm{c}}=2 \times \bar{\varepsilon}_{\mathrm{c}}^{2} \times 0.5^{\bar{\varepsilon}_{\mathrm{c}}}{ }^{3} \text {. }
$$

The corresponding satisfactory overall $R^{2}$ value of 0.917 indicated that stresses of earth materials can be well predicted by (7), as shown in Figure 12.

Figure 12 shows the comparison of the stress-strain model derived in this study with the models proposed by Zhang et al. [28], Illampas et al. [29], and Adorni et al. [30], respectively. Equation (8) reported in [30] was calibrated by experimental data from uniaxial compression test on earth blocks with the ratio of height to thickness $\beta>1$. It was noted that (8) was only fitted to the ascending branch of the stress-strain curve, and the equation neglected the compaction phase of earth materials at the initial stage of loading.

$$
\bar{f}_{\mathrm{c}}=\frac{4.11 \times \bar{\varepsilon}_{\mathrm{c}}}{3.11+\bar{\varepsilon}_{\mathrm{c}}^{4.11}}
$$

Further from Adorni's model, Rogiros Illampas used a piecewise function to fit the stress-strain curve of earth blocks and proposed (9). Although (9) contained the descending branch of the stress-strain curve, it still did not reflect the compaction phase. Furthermore, the continuity of (9) and its first derivative cannot be guaranteed at the piecewise point:

$\bar{f}_{\mathrm{c}}=\bar{\varepsilon}_{\mathrm{c}} \begin{cases}1.441 \bar{\varepsilon}_{\mathrm{c}}+0.119 \bar{\varepsilon}_{\mathrm{c}}^{2}-0.559 \bar{\varepsilon}_{\mathrm{c}}^{3} & \text { for } 0 \leq \bar{\varepsilon}_{\mathrm{c}} \leq 1.07 \\ 1.266-0.285 \bar{\varepsilon}_{\mathrm{c}}+0.028 \bar{\varepsilon}_{\mathrm{c}}^{2}-0.0001 \bar{\varepsilon}_{\mathrm{c}}^{3} & \text { for } 1.07 \leq \bar{\varepsilon}_{\mathrm{c}} \leq 4 .\end{cases}$ 
TABLE 4: $R^{2}$ of different constitutive modes.

\begin{tabular}{lc}
\hline Constitutive model & $R^{2}$ \\
\hline Elisa Adorni & 0.807 \\
Rogiros Illampas & 0.823 \\
Youchao Zhang & 0.836 \\
Equation (1) & 0.915
\end{tabular}

After that, Youchao Zhang recommended a constitutive model reflecting the compaction phase of earth materials. For (10), exponential function and linear function were used to fit the ascending and descending branches of the stressstrain curve, respectively. However, not only this piecewise function did not pass through the origin but also its first derivative was discontinuous at the piecewise point. The equation proposed in this study overcomes the defects of above constitutive equations. The satisfactory overall $R^{2}$ values of different constitutive equations were listed in Table 4 . The parameters $R^{2}$ of (7) was the largest, and it also indicated that (7) was preferable to the other three model:

$$
\bar{f}_{\mathrm{c}}=\bar{\varepsilon}_{\mathrm{c}} \begin{cases}e^{-5.3\left(\bar{\varepsilon}_{\mathrm{c}}-1\right)^{2}} & \text { for } \bar{\varepsilon}_{\mathrm{c}} \leq 1 \\ 1.5-0.5 \bar{\varepsilon}_{\mathrm{c}} & \text { for } \bar{\varepsilon}_{\mathrm{c}}>1 .\end{cases}
$$

\section{Conclusions}

This study aimed to evaluate the influences of specimen geometry and loading rate on the mechanical property of compressed earth block used in simple compression tests. Based on the analysis of results, the following main conclusions can be drawn:

(i) The effect of specimen size on the compressive strength was evident in simple compression tests. The unconfined compressive strength decreases with the increase in specimen size. This phenomenon was due to the compound influence of plate constraint effect and distribution inhomogeneity of earth materials defects.

(ii) The effect of loading rate on the compressive strength was insignificant. It may be due to the narrow range of loading rates chosen in this study. Further research work was required to investigate the loading rate effects on the compressive strength under a wide range of loading rate.

(iii) The effect of specimen shape was trivial in unconfined compressive tests. The cylindrical specimens are given slightly higher compressive strength than the cubic specimens at different loading rates. The maximum difference in the compressive strength was less than $8.4 \%$, indicating that the shape effect on compressive strength was negligible.

(iv) According to the variability of test data, $100 \mathrm{~mm}$ cube was recommended as a standard specimen, and $3 \mathrm{~mm} / \mathrm{min}$ was selected as the standard loading rate in the simple compression test.

(v) Based on the experimental results, a constitutive model for describing CEBs' stress-strain behavior under compression was proposed. Defects in the previous studies were modified in the constitutive model. It was expected that the constitutive model can be applied in the numerical calculation of the earth structure.

(vi) Besides the geometric effect and loading rate effect, the influence of manufacture method and test method were significant in the compression test. The next paper will be systematically studied for these two points.

\section{Data Availability}

All data generated or analyzed during this study are included in the article.

\section{Ethical Approval}

Compliance with Ethical Standards: Enclosed is the manuscript of the above article, which we would like to submit the manuscript to "Advances in Materials Science and Engineering." This manuscript is the author's original work and has not been published nor has it been submitted simultaneously elsewhere.

\section{Conflicts of Interest}

The authors declare that they have no conflicts of interest.

\section{Acknowledgments}

The work described in this article is part of a research project on the "Study on the Standard Test Method of Materials and Masonry Based on Raw-soil" funded by the "Science Fund for Creative Research Groups of the National Natural Science Foundation of China" under Grant no. 51478043.

\section{References}

[1] L. Widder, "Earth eco-building: textile-reinforced earth block construction," Energy Procedia, vol. 122, pp. 757-762, 2017.

[2] H. V. Damme and H. Houben, "Earth concrete. Stabilization revisited," Cement and Concrete Research, 2017, In press.

[3] M. B. Mansour, A. Jelidi, A. S. Cherif et al., "Optimizing thermal and mechanical performance of compressed earth blocks (CEB)," Construction and Building Materials, vol. 104, pp. 44-51, 2016.

[4] N. M. Miller and F. M. Tehrani, "Mechanical properties of rubberized lightweight aggregate concrete," Construction and Building Materials, vol. 147, pp. 264-271, 2017.

[5] T. Sturm, L. F. Ramos, and P. B. Lourenço, "Characterization of dry-stack interlocking compressed earth blocks," Materials and Structures, vol. 48, no. 9, pp. 3059-3074, 2015.

[6] L. F. Cabeza, C. Barreneche, L. MirÓ et al., "Low carbon and low embodied energy materials in buildings: a review," Renewable and Sustainable Energy Reviews, vol. 23, pp. 536-542, 2013.

[7] M. Achenza and L. Fenu, "On earth Stabilization with natural polymers for earth masonry construction," Materials and Structures, vol. 39, no. 1, pp. 21-27, 2006.

[8] L. Miccoli, D. V. Oliveira, A. S. Rui et al., "Static behaviour of rammed earth: experimental testing and finite element 
modelling," Materials and Structures, vol. 48, no. 10, pp. 3443-3456, 2015.

[9] F. Pacheco-Torgal and S. Jalali, "Earth construction: lessons from the past for future eco-efficient construction," Construction and Building Materials, vol. 29, no. 4, pp. 512-519, 2012.

[10] P. Zak, T. Ashour, A. Korjenic et al., "The influence of natural reinforcement fibers, gypsum and cement on compressive strength of earth bricks materials," Construction and Building Materials, vol. 106, pp. 179-188, 2016.

[11] D. Ciancio and J. Gibbings, "Experimental investigation on the compressive strength of cored and molded cementstabilized rammed earth samples," Construction and Building Materials, vol. 28, no. 1, pp. 294-304, 2012.

[12] F. Wu, G. Li, H. N. Li et al., "Strength and stress-strain characteristics of traditional adobe block and masonry," Materials and Structures, vol. 46, no. 9, pp. 1449-1457, 2013.

[13] B. V. V. Reddy and A. Gupta, "Characteristics of soil-cement blocks using highly sandy soils," Materials and Structures, vol. 38, no. 6, pp. 651-658, 2005.

[14] Standards Australia Handbook 194, The Australian Earth Building Handbook, Standards Australia, Sydney, Australia, 2002.

[15] New Zealand Standard 4298, Materials and Workmanship for Earth Buildings, Standards New Zealand, New Zealand, 1998.

[16] J. C Morel, A. Pkla, and P. Walker, "Compressive strength testing of compressed earth blocks," Construction and Building Materials, vol. 21, no. 2, pp. 303-309, 2007.

[17] D. Silveira, H. Varum, and A. Costa, "Influence of the testing procedures in the mechanical characterization of adobe bricks," Construction and Building Materials, vol. 40, no. 3, pp. 719-728, 2013.

[18] J. E. Aubert, P. Maillard, J. C. Morel et al., "Towards a simple compressive strength test for earth bricks?," Materials and Structures, vol. 49, no. 5, pp. 1641-1654, 2016.

[19] Y. L. Chen, L. Q. Chang, and S. Xu, "Experimental study on uniaxial compressive strength," Journal of Shanghai University (Natural Science), vol. 15, no. 3, pp. 310-315, 2009.

[20] H. M. Du, W. Ma, and S. J. Zhang, "Effects of strain rate and water content on uniaxial compressive characteristics of frozen soil," Rock and Soil Mechanics, vol. 37, no. 5, pp. 1373-1379, 2016.

[21] X. X. Zhang, G. Ruiz, and A. M. A. Elazim, "Loading rate effect on crack velocities in steel fiber-reinforced concrete," International Journal of Impact Engineering, vol. 76, pp. 60-66, 2015.

[22] H. Xu and H. M. Wen, "Semi-empirical equations for the dynamic strength enhancement of concrete-like materials," International Journal of Impact Engineering, vol. 60, no. 60, pp. 76-81, 2013.

[23] X.-h. Wang, S.-r. Zhang, C. Wang, R. Song, C. Shang, and $\mathrm{X}$. Fang, "Experimental investigation of the size effect of layered roller compacted concrete (RCC) under high-strainrate loading," Construction and Building Materials, vol. 165, pp. 45-57, 2018.

[24] F. Parisi, D. Asprone, L. Fenu et al., "Experimental characterization of Italian composite adobe bricks reinforced with straw fibers," Composite Structures, vol. 122, pp. 300-307, 2015.

[25] Standards Chinese Standard SL237-1999, Specification of Soil Test, Standards Chinese, Beijing, China, 1999.

[26] Standards Chinese Standard GB T 50145-2007, Standard for Engineering Classification of Soil, Standards Chinese, Beijing, China, 2007.
[27] Standards Chinese Standard GB/T 50081-2002, Test Method of Mechanical Properties on Ordinary Concrete, Standards Chinese, Beijing, China, 2002.

[28] Y. Zhang, Y. Wang, N. Zhao, and T. Wang, "Experimental and stress-strain equation investigation on compressive strength of raw and modified soil in loess plateau," Advances in Materials Science and Engineering, vol. 2016, no. 203, pp. 1-10, 2016.

[29] R. Illampas, I. Ioannou, and D. C. Charmpis, "Adobe bricks under compression: experimental investigation and derivation of stress-strain equation," Construction and Building Materials, vol. 53, no. 4, pp. 83-90, 2014.

[30] E. Adorni, E. Coïsson, and D. Ferretti, "In situ characterization of archaeological adobe bricks," Construction and Building Materials, vol. 40, no. 7, pp. 1-9, 2013. 


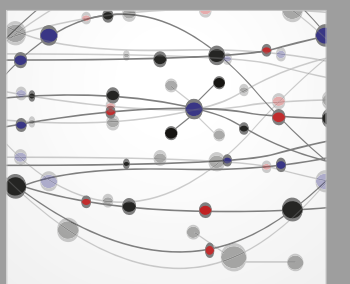

The Scientific World Journal
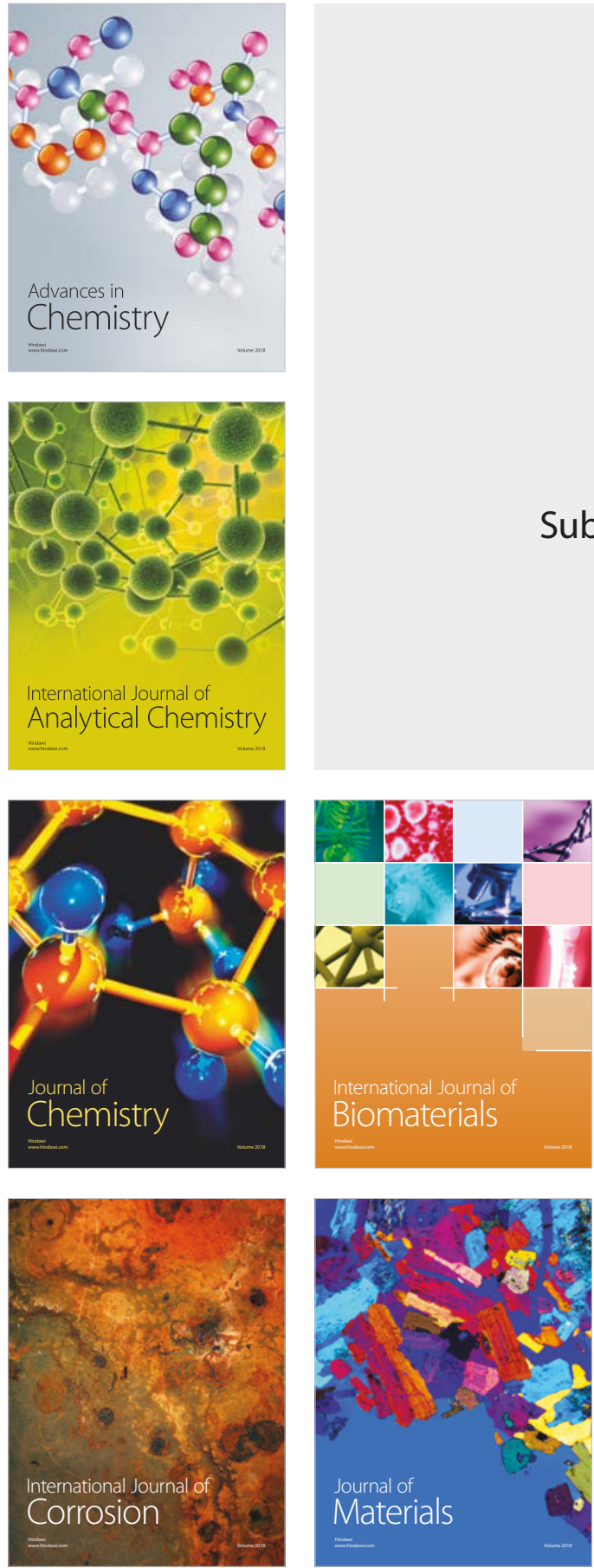

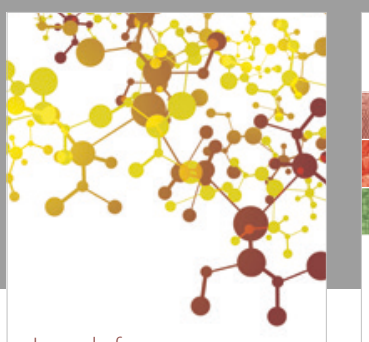

Journal of

Applied Chemistry
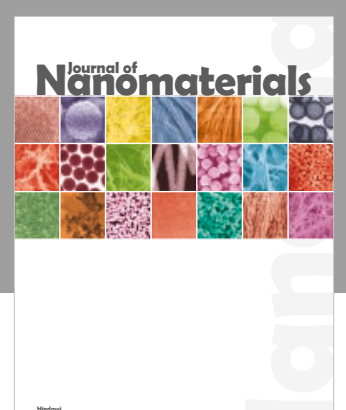

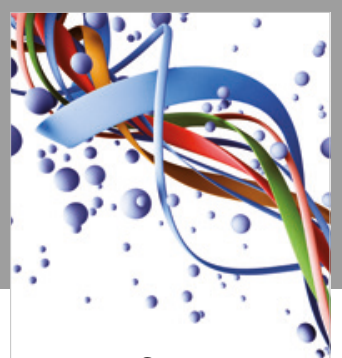

Scientifica

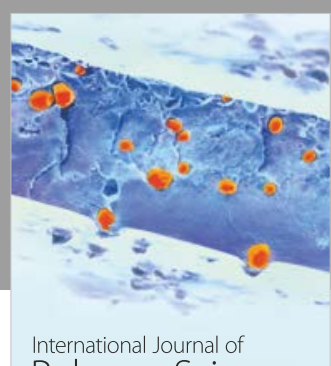

Polymer Science

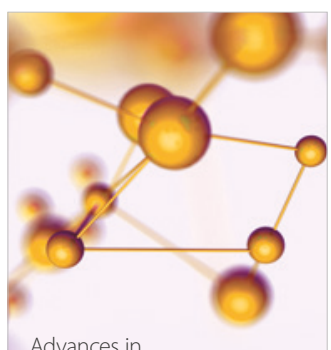

Physical Chemistry
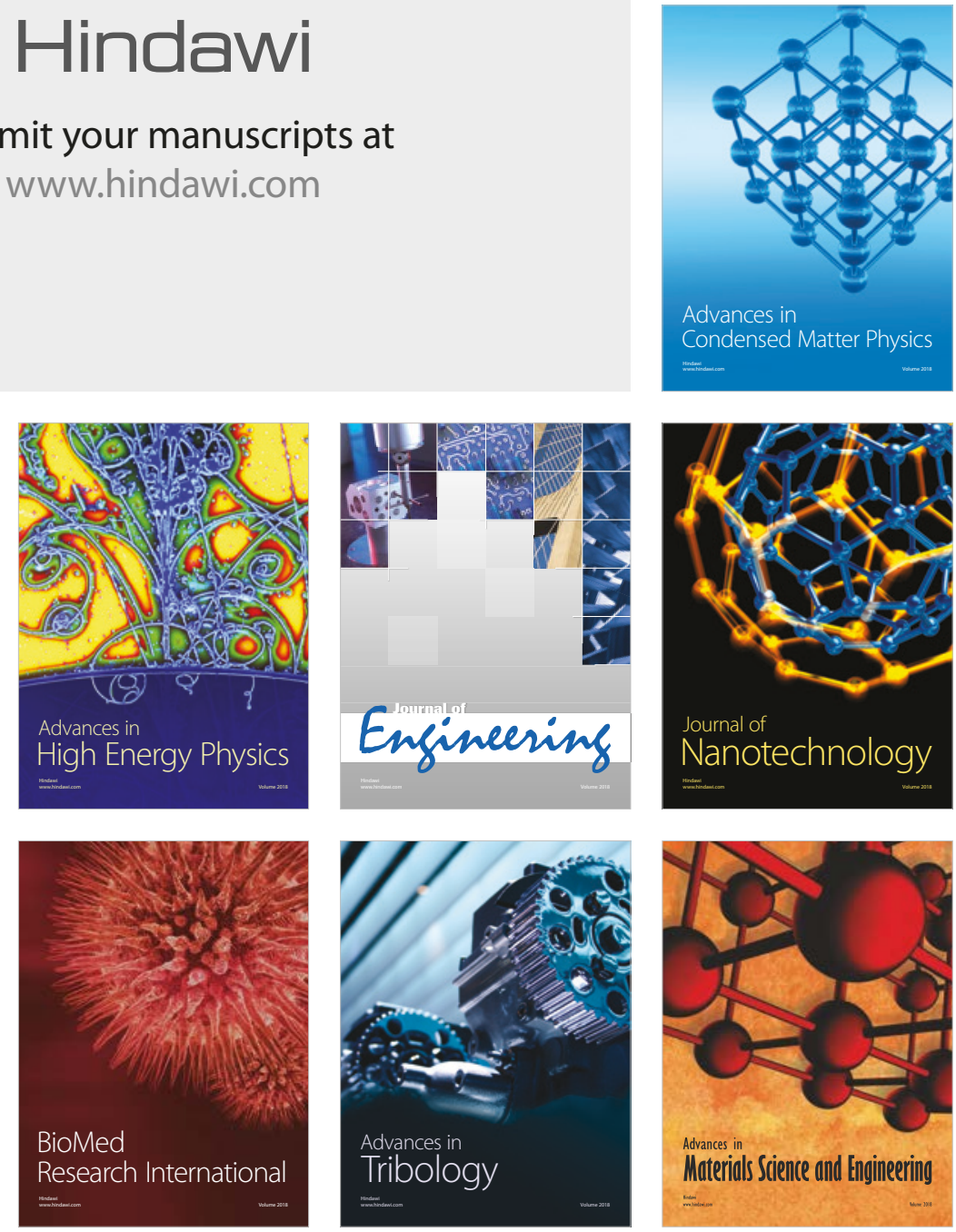